\title{
Ternary Multicomponent Adsorption Modelling Using ANN, LS-SVR, and SVR Approach - Case Study
}

\author{
A. Yettou, ${ }^{a}$ M. Laidi, ${ }^{a}{ }^{*}$ A. El Bey, ${ }^{a}$ S. Hanini, ${ }^{a}$ \\ M. Hentabli, ${ }^{\text {b }}$. Khaldi, ${ }^{c}$ and M. Abderrahima \\ a Laboratory of Biomaterials and Transport Phenomena (LBMPT), University of Médéa, Algeria \\ ${ }^{b}$ Laboratory Quality Control, Physico-Chemical Department, \\ Antibiotical Saidal of Médéa, Algeria \\ c Material and Environment Laboratory (LME), University Yahia Fares of Medea, Médéa, Algeria
}

https://doi.org/10.15255/KUI.2020.071

KUI-36/2021

Original scientific paper

Received October 28, 2020

Accepted January 15, 2021

\begin{abstract}
The aim of this work was to develop three artificial intelligence-based methods to model the ternary adsorption of heavy metal ions $\left\{\mathrm{Pb}^{2+}, \mathrm{Hg}^{2+}, \mathrm{Cd}^{2+}, \mathrm{Cu}^{2+}, \mathrm{Zn}^{2+}, \mathrm{Ni}^{2+}, \mathrm{Cr}^{4+}\right\}$ on different adsorbates \{activated carbon, chitosan, Danish peat, Heilongjiang peat, carbon sunflower head, and carbon sunflower stem). Results show that support vector regression (SVR) performed slightly better, more accurate, stable, and more rapid than least-square support vector regression (LS-SVR) and artificial neural networks (ANN). The SVR model is highly recommended for estimating the ternary adsorption kinetics of a multicomponent system.
\end{abstract}

\section{Keywords}

Multicomponent adsorption, heavy metals, artificial neural networks, support vector regression, least-square support vector regression

\section{Introduction}

Due to increasing concentrations of various toxic and non-biodegradable contaminants like heavy metals in industrial wastewater, which have an adverse effect on human health and the environment, ${ }^{1}$ various purification techniques have been proposed for wastewater treatment; adsorption is commonly being employed because of its high removal capacity of heavy metal ions using different adsorbents, low-cost of installation, operation and maintenance, and simple design. ${ }^{2}$ Heretofore, numerous studies have reported the simultaneous interactions of multicomponent adsorption phenomenon of heavy metal ions on the adsorbent. ${ }^{3-5}$ To design the adsorption equipment, it is mandatory to know the adsorption mechanisms. Thus, various empirical and theoretical models have been proposed in the literature to evaluate the equilibrium adsorption of heavy metals, namely Langmuir, Freundlich, Toth, and other models. ${ }^{6}$ Since the multicomponent adsorption process is highly complex phenomena explained by the competition and interaction nature (synergism, synergism and non-interaction) ${ }^{7}$ between adsorbent and multiple adsorbates, as well as operating conditions $(\mathrm{pH}$, time, temperature, and concentration), it is difficult to model using the theoretical models. ${ }^{8}$

Various artificial intelligence methods are presented in the literature to overcome the limitations of the theoretical models. Most of them are established to model the removal of a single heavy metal, but few discuss the application of these models to model the multicomponent heavy met-

* Corresponding author: Dr Maamar Laidi

Email: maamarw@yahoo.fr al adsorption process. ${ }^{9,10}$ ANNs are applied successfully to model the non-linear behaviour between dependent and independent variables without knowing any previous details about the physical process in complex systems., ${ }^{71-14}$ However, to the best of our knowledge, very few studies are devoted to the application of LS-SVM or SVM approach to model the competitive adsorption of heavy metals. ${ }^{15,16}$

Therefore, the major motivation behind this study was to assess the predictability power of three modelling approaches $\{A N N, S V M$, and LS-SVM $\}$ in modelling the nonlinear relationships between the removal capacity from aqueous solution of five ternary heavy metal systems on different adsorbents and the independent parameters. The experimental data set employed in this work to optimise the three model parameters was extracted from previously published literature. The performance of these models will be evaluated using well-known statistical metrics and compared with the experimental data.

\section{Modelling approaches}

\subsection{ANN model}

Artificial neural network (ANN) by its similarity with human brain functionality, can learn the complex relationship between the response and its effecting parameters from previous experimental data set, and can use the obtained knowledge in future predictions. The performance of the ANN depends on some parameters, such as the number of hidden layers and the number of neurons in each hidden layer, the transfer function, and the normalisation func- 
tion. ${ }^{17,18}$ The output of each hidden neuron (j) can be written in the following form in terms of inputs $X_{i}$, weights and biases, and the transfer function $f(x):{ }^{19}$

$$
H_{j}^{\mathrm{O}}=f\left(\sum_{i=1}^{1} X_{i} \cdot W_{i j}+b_{j}\right)
$$

The final output $(k)$ can also be expressed in the following form: ${ }^{19}$

$$
O_{k}^{O}=f\left(\sum_{j=1}^{J} H_{j}^{O} \cdot W_{j k}+b_{k}\right)
$$

The transfer function, weights and biases can be determined during the training stage.

\subsection{LS-SVM and SVM model}

Support vector machine (SVM) presents a number of superiorities in comparison to ANN, it can map the nonlinear relationship between inputs and output(s) avoiding to be stocked into local minima, it can solve problems using only support vector and it can deal with small data set. ${ }^{20,21}$ The performance of SVM model can be determined based on the selected kernel function and its parameters. ${ }^{16}$ The predicted output can be expressed via SVM model as follows: ${ }^{16}$

$$
y(x)_{\text {pre }}=\sum_{i=1}^{n} \alpha_{i} \cdot K\left(x_{i}, x_{j}\right)+b
$$

where $K\left(x_{i}, x_{j}\right)$ can be linear, polynomial, Gaussian or radial basis function kernel. $\alpha_{i}$ and $b$ denote Lagrange multiplier and threshold parameter, respectively. In support vector regression, it is mandatory to optimise the following expression: ${ }^{16}$

$$
\frac{1}{2} W^{2}+C \sum_{i=1 i}^{n}
$$

where $W$ denotes the margin and represents the complexity of the SVM model, $\sum_{i=1 i}^{n}$ represents the sum of the training errors, and $C$ is a tuning parameter. Compared to the conventional SVM, LS-SVM can convert the inequality constraints into equality constraints. ${ }^{21}$

\section{ANN, LS-SVR, and SVR modelling}

\subsection{Data set collection and processing}

The data set used in this work has been collected from previously published papers in literature and organised in a matrix of $\{84$ points, 11 parameters $\}$ including 8 inputs

\begin{tabular}{|c|c|c|c|c|}
\hline Sys. & Adsorbates & Adsorbent & $\begin{array}{c}\text { Data } \\
\text { points }\end{array}$ & Ref. \\
\hline 1 & $\mathrm{~Pb}^{2+}+\mathrm{Hg}^{2+}+\mathrm{Cd}^{2+}$ & Activated carbon & 15 & 22 \\
\hline 2 & $\mathrm{~Pb}^{2+}+\mathrm{Cu}^{2+}+\mathrm{Zn}^{2+}$ & Chitosan & 20 & 23 \\
\hline \multirow{2}{*}{3} & \multirow{2}{*}{$\mathrm{Pb}^{2+}+\mathrm{Cu}^{2+}+\mathrm{Cd}^{2+}$} & Danish peat & 10 & \multirow{2}{*}{24} \\
\hline & & Heilongjiang peat & 10 & \\
\hline \multirow{2}{*}{4} & \multirow{2}{*}{$\mathrm{Ni}^{2+}+\mathrm{Cr}^{4+}+\mathrm{Cd}^{2+}$} & Carbon sunflower head & 8 & \multirow[t]{2}{*}{25} \\
\hline & & Carbon sunflower stem & 8 & \\
\hline 5 & $\mathrm{Zn}^{2+}+\mathrm{Cu}^{2+}+\mathrm{Cd}^{2+}$ & Activated carbon & 13 & 26 \\
\hline
\end{tabular}
and 3 outputs. Table 1 presents details and sources of the selected data set.
Table 1 - Details of the used data set

The data set was divided into 8 inputs explained as follows: BET surface, structure index of each adsorbent (micropores, mesopores, macropores), molecular weight of each compound $\left(M_{\mathrm{w} 1}, M_{\mathrm{w} 2}\right.$ and $\left.M_{\mathrm{w} 3}\right)$, initial concentration for each compound $\left(C_{\mathrm{e} 1}, C_{\mathrm{e} 2}, C_{\mathrm{e} 3}\right)$ and the removal capacity of each heavy metal ion $\left(q_{\mathrm{e} 1}, q_{\mathrm{e} 2}\right.$, and $\left.q_{\mathrm{e} 3}\right)$ as outputs.

The data set was divided randomly: $74 \%$ for training and $26 \%$ for the test stage (case of SVR and LS-SVR model), and $76 \%$ for training, $12 \%$ for the test, and $12 \%$ for validation (case of ANN model). In order to ensure the rapid convergence of the models, a normalisation stage of inputs was done using the proposed function expressed by expression 4, while the outputs were normalised/post-normalised using the two functions programmed in MATLAB \{premnmx $(Y) /$ postmnmx $(Y)\}$ as represented in expressions 5 and 6 , respectively. The aim of the normalisation was to have the data in the same range and avoid greater errors. ${ }^{21}$

$$
\begin{gathered}
X_{n}=\sqrt[0.59]{x} \\
y_{n}=\frac{2\{Y-\min (Y)\}}{\{\max (Y)-\min (Y)\}}-1 \\
Y=0.5\left(y_{n}+1\right)\{\max (Y)-\min (Y)\}+\min (Y)
\end{gathered}
$$

\subsection{Performance analysis of developed models}

The performance of these models was assessed using two metrics, namely, the mean squared error (MSE) and the determination coefficient $\left(R^{2}\right)$ :

$$
\begin{array}{r}
\text { MSE }=\frac{1}{N} \sum_{i=1}^{N}\left(y_{i \text { exp }}-y_{\text {ical }}\right)^{2} \\
R^{2}=1-\frac{\sum_{i=1}^{N}\left(y_{i \exp }-y_{i \text { cal }}\right)^{2}}{\sum_{i=1}^{N}\left(y_{i \exp }-\bar{y}_{i \exp }\right)^{2}}
\end{array}
$$

where $N$ is the number of points, $y_{\text {iexp }}, y_{i c a l}$ and $\bar{y}_{i \exp }$ are the experimental, calculated, and mean of the experimental 
target vectors. These metrics explain how well the model can predict the experimental data. ${ }^{27}$ Better accuracy of the model can be found when $R^{2}$ is close to 1 and MSE is close to 0 .

\section{Modelling results and discussion}

\subsection{ANN model}

In this work, a multi-layer perceptron (MLP) was selected and trained with Levenberg-Marquardt algorithm. Hyperbolic tangent and linear function was adopted in the hidden and the output layers, respectively. Table 2 presents the mathematical expression of these two transfer functions. The flowchart of ANN model development is presented in Fig. 1. This procedure was programmed in MATLAB software.

Since there are no rules for the exact determination of the ANN parameters, a trail-and-error method was adopted and based on the obtained values of the selected metrics. Details of the best ANN model parameters are presented in Table 3.

Fig. 2 shows a comparison between the experimental and predicted values of the removal capacity of the three heavy

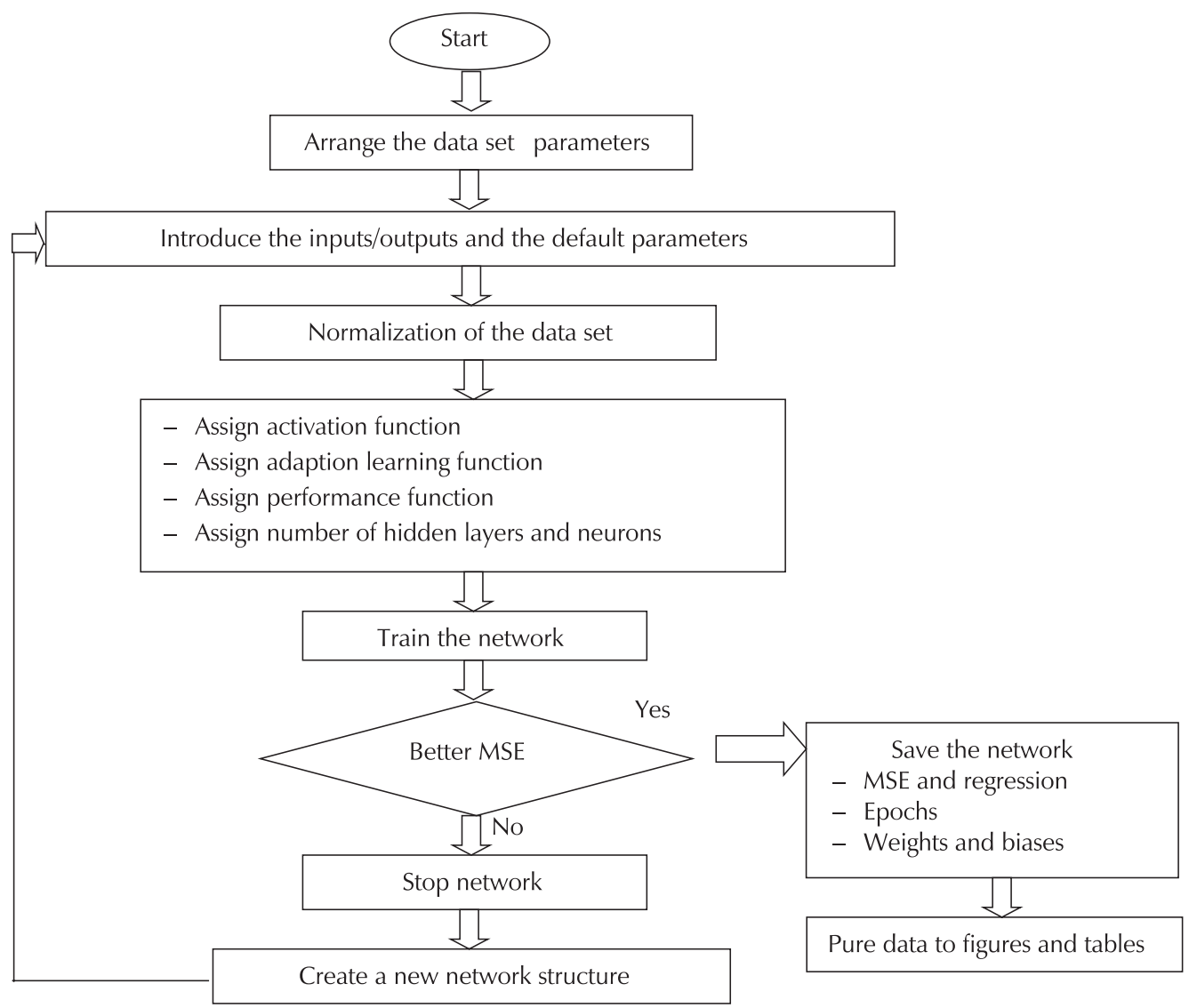

Fig. 1 - Flowchart of the ANN network development procedures

Table 2 - Expression of the transfer functions and their codes in MATLAB

\begin{tabular}{c|c|c|c}
\hline Transfer function & Expression & Plot \\
\hline Hyperbolic tangent & $a=\frac{\mathrm{e}^{+n}-\mathrm{e}^{-n}}{\mathrm{e}^{+n}+\mathrm{e}^{-n}}$ & \\
\hline Linear & $\mathrm{a}=\mathrm{n}$ & $\mathrm{P}$ \\
\hline
\end{tabular}


Table 3 - Structure and parameters of the best ANN model

\begin{tabular}{c|c|c}
\hline ANN type & \multicolumn{2}{|c}{ Feedforward-backpropagation neural network (MATLAB code: newff) } \\
\hline ANN structure & Neurons number & Transfer function \\
\hline Layers & 8 & \\
\hline Input & 6 & $f_{\mathrm{h}}$ : hyperbolic tangent functions \\
\hline Hidden & 3 & $f_{\mathrm{o}}$ : Linear function \\
\hline Output & \multicolumn{2}{c}{ Levenberg-Marquardt (MATLAB code: trainlm) } \\
\hline
\end{tabular}
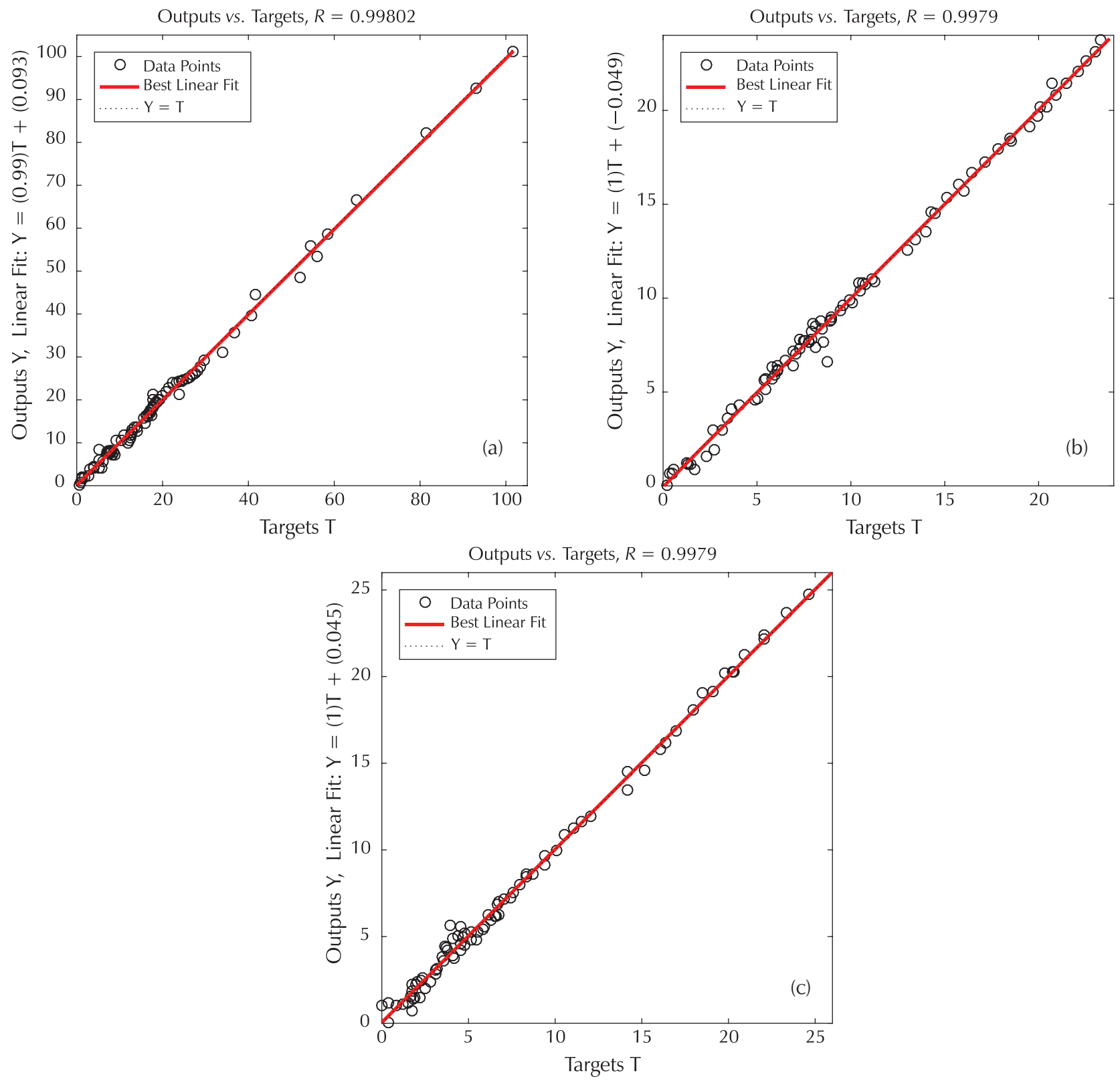

Fig. 2 - Experimental vs. predicted removal capacity during the generalisation stage a) for $q_{\mathrm{e} 1}$, b) for $q_{\mathrm{e} 2}$, and c) for $q_{\mathrm{e} 3}$ 
metal ions for the global data set. According to these figures, we can observe the perfect alignment of all points on the best linear fit, where the values of $R^{2}$ for the three removal capacities are superior to 0.99 during the generalisation stage. These results confirm the high ability of the obtained ANN model to capture the experimental features quite accurately.

Table 4 - Metrics comparison for the best ANN model

\begin{tabular}{l|c|r|c}
\hline & $\begin{array}{r}\text { Removal } \\
\text { capacity }\end{array}$ & \multicolumn{3}{|c|}{$q_{\mathrm{e} 1}$} & $q_{\mathrm{e} 2}$ & $q_{\mathrm{e} 3}$ \\
\cline { 3 - 4 } $\begin{array}{l}\text { Statistical } \\
\text { parameters }\end{array}$ & \multicolumn{3}{|c}{ Generalisation stage } \\
\hline determination coefficient $\left(R^{2}\right)$ & 0.9960 & 0.9957 & 0.9958 \\
\hline correlation coefficient $(R)$ & 0.9980 & 0.9979 & 0.9979 \\
\hline slope $(\alpha)$ & 0.9944 & 1.0038 & 0.9995 \\
\hline intercept $(\beta)$ & 0.0932 & -0.0489 & 0.0454 \\
\hline mean squared error $(\mathrm{MSE})$ & $\mathbf{1 . 4 8 9 8}$ & $\mathbf{0 . 1 7 8 0}$ & $\mathbf{0 . 1 9 1 2}$ \\
\hline
\end{tabular}

Table 4 presents different metric comparison for the generalisation stage. It can be seen that the ANN performs well when predicting $q_{\mathrm{e} 2}$ and $q_{\mathrm{e} 3}$ rather than $q_{\mathrm{e} 1}$. Overall, the developed ANN model was found with very low MSE value and high $R^{2}$ value.

The mathematical formula that connects the inputs to each output via the optimised neural network (ANN) is given by equations 9 to 11:

$$
q_{\mathrm{e} 1}=f_{\mathrm{o}}\left(\sum_{k=1}^{6}\left(w_{1 k} \cdot f_{\mathrm{h}}\left(\sum_{j=1}^{8}\left(w_{k j} \cdot X_{j}+b_{h j}\right)\right)+b_{1 k}\right)\right)
$$

$$
\begin{aligned}
& q_{\mathrm{e} 2}=f_{\mathrm{o}}\left(\sum_{k=1}^{6}\left(w_{2 k} \cdot f_{\mathrm{h}}\left(\sum_{j=1}^{8}\left(w_{k j} \cdot X_{j}+b_{h j}\right)\right)+b_{2 k}\right)\right) \\
& q_{\mathrm{e} 3}=f_{\mathrm{o}}\left(\sum_{k=1}^{6}\left(w_{3 k} \cdot f_{\mathrm{h}}\left(\sum_{j=1}^{8}\left(w_{k j} \cdot X_{j}+b_{h j}\right)\right)+b_{3 k}\right)\right)
\end{aligned}
$$

where $w_{\mathrm{kj}}$ and $b_{\mathrm{hj}}$ denote weights and biases between inputs-hidden layer. $w_{1 \mathrm{k}}$ and $b_{1 \mathrm{k}}$ denote weights and biases between hidden-output layer. $f_{\mathrm{o}}$ and $f_{\mathrm{h}}$ are linear and tangent hyperbolic transfer function. Weight and biases matrix of the proposed optimal ANN-MLP model are presented in Tables 5 and 6 to allow other researchers to reproduce results and make appropriate use of this ANN-MLP model.

An example of the comparison between experimental and predicted values is given in Fig. 3. It shows that the points

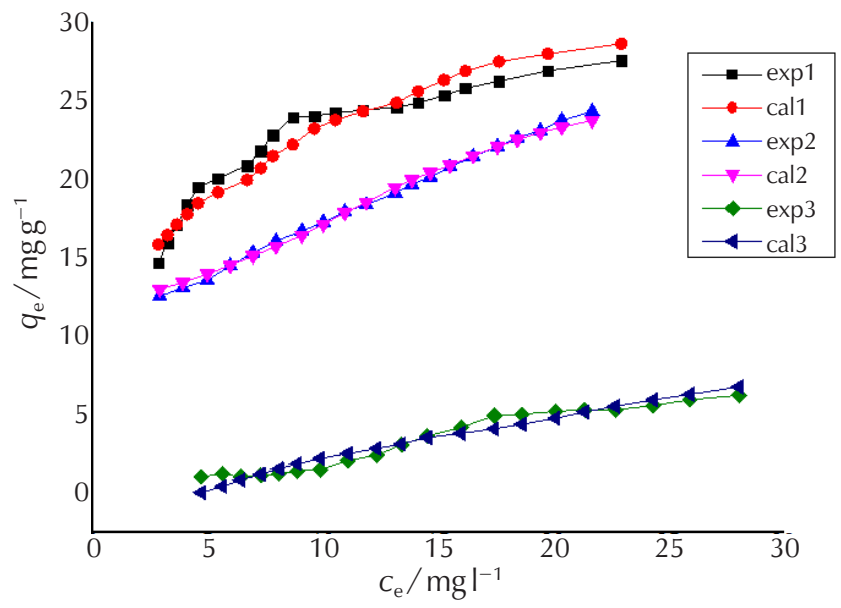

Fig. 3 - Predicted by ANN vs experimental removal capacity of the ternary system against concentration

Table 5 - Weights and biases values of the best ANN-MLP between inputs and hidden layer

\begin{tabular}{r|r|r|r|r|r|r|r|r}
\hline \multicolumn{9}{|c}{ Weight between inputs-hidden layer } \\
\hline 3.778 & 0.345 & 0.580 & -3.259 & 3.651 & -0.443 & 0.372 & 1.034 & -3.018 \\
\hline 6.121 & -0.022 & 4.511 & -4.826 & 1.029 & -19.930 & 24.120 & -2.290 & -1.745 \\
\hline-702.409 & 4.536 & -35.716 & 543.451 & -10.606 & 134.855 & -46.405 & 41.627 & -48.875 \\
\hline 58.313 & -59.610 & -7.310 & 34.432 & -31.834 & -0.299 & 0.558 & 0.176 & 56.870 \\
\hline 159.742 & -0.877 & 8.441 & -124.056 & 24.288 & -1.715 & 4.917 & -5.145 & 15.556 \\
\hline-0.440 & 0.288 & 1.919 & -12.676 & -5.900 & 0.393 & -0.526 & -0.255 & -4.160 \\
\hline
\end{tabular}

Table 6 - Weights and biases values of the best ANN-MLP between hidden and output layer

\begin{tabular}{r|r|r|r|r|r|r}
\hline \multicolumn{7}{|c}{ Weight between hidden-output layer } \\
bias \\
\hline 1.3632 & 0.0382 & 0.5056 & 21.9631 & -0.7906 & 22.1628 & -0.904 \\
\hline 1.0129 & 0.2439 & 0.9787 & 54.8302 & -0.1795 & 54.9675 & -0.8653 \\
\hline-0.0414 & -0.0639 & 2.1612 & 73.8696 & 2.1714 & 73.9097 & -0.5996 \\
\hline
\end{tabular}


predicted by ANN follow exactly and match well the trend of the experimental points, which confirms the capability of the ANN model to model the non-linear behaviour of the multicomponent adsorption system of the selected heavy metal ions.

\subsection{LS-SVR model}

For LS-SVR and SVR, different kernel functions have been tested to model multicomponent adsorption system. Table 7 represents the expression of these functions.
Table 7 - Kernel functions tested for LS-SVR and SVR ${ }^{28}$

\begin{tabular}{l|c}
\hline Name of the kernel & Mathematical formula \\
\hline Linear kernel & $k(x, y)=x \cdot y+c$ \\
\hline Gaussian kernel & $k(x, y)=\exp \left(\frac{-|| x-y||^{2}}{2 \sigma^{2}}\right)$ \\
\hline $\begin{array}{l}\text { Radial basis function } \\
\text { kernel }\end{array}$ & $f(x)=\sum_{i}^{N} a_{i} y_{i} \exp \left(\frac{-|| x-x_{i}||^{2}}{2 \sigma^{2}}\right)+b$ \\
\hline Polynomial kernel & $k(x, y)=(a x \cdot y+c)^{d}$ \\
\hline
\end{tabular}
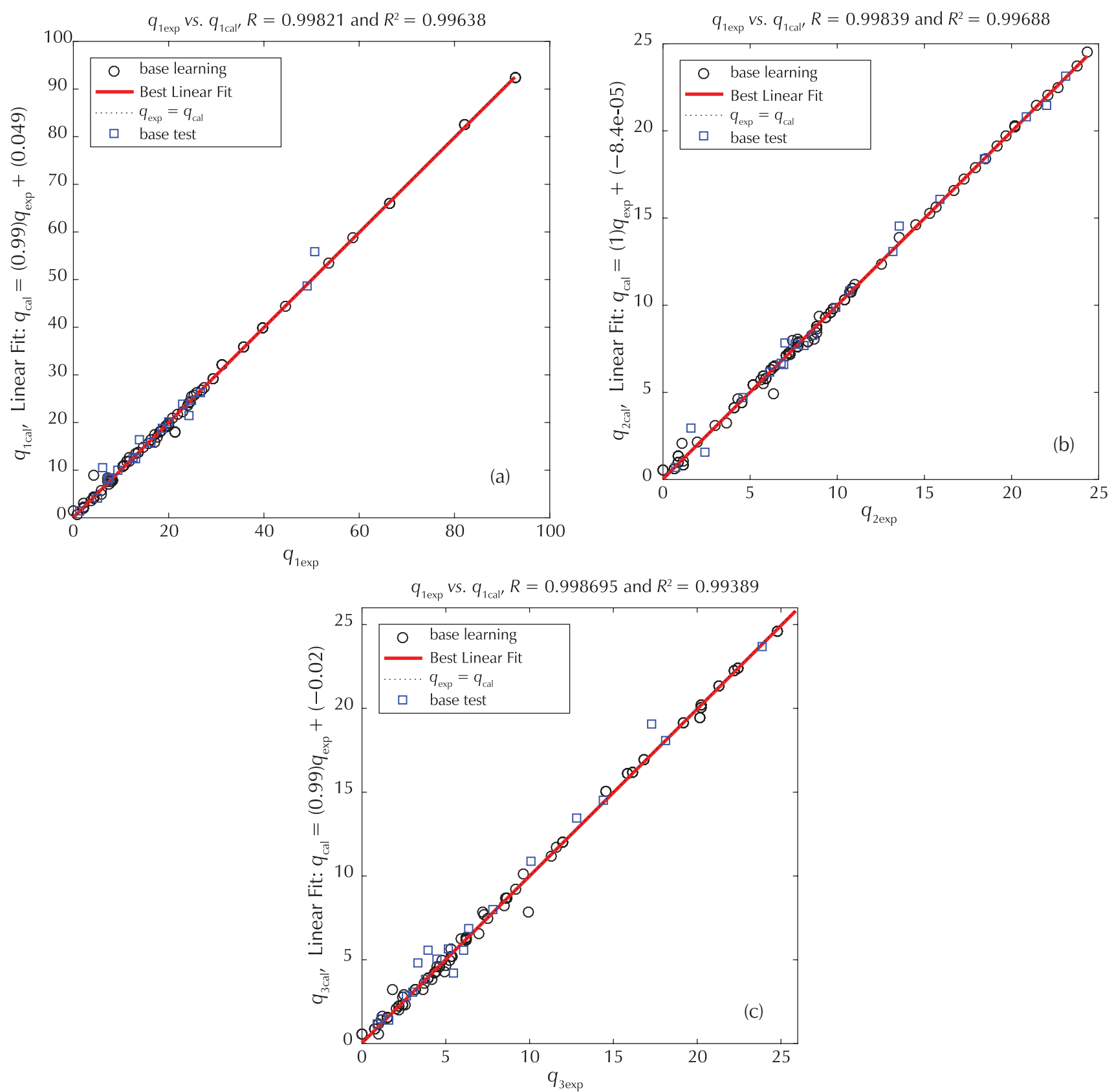

Fig. 4 - Predicted vs experimental adsorption capacity using LS-SVR, a) for $q_{\mathrm{e} 1}$, b) for $q_{\mathrm{e} 2}$, and c) for $q_{\mathrm{e} 3}$ 
With the selected LS-SVR structure, the maximum MSE of 1.3571 and $R^{2}$ above 0.99 were obtained during the generalisation stage. As may be seen in Fig. 4, all predicted points are very close and around the unity line, showing the satisfactory and robust LS-SVR.

The performance of the developed LS-SVR model was further analysed through the calculation of some metrics (Table 8).

\subsection{SVR model}

Compared to the LS-SVR and ANN models, the prediction accuracy of the SVR model was higher. Fig. 5 shows
Table 8 - Computed errors comparison results obtained by LS-SVR

\begin{tabular}{l|c|c|c}
\hline \multirow{2}{*}{$\begin{array}{r}\text { Removal } \\
\text { Stapacity } \\
\text { carametical }\end{array}$} & $q_{\mathrm{e} 1}$ & $q_{\mathrm{e} 2}$ & $q_{\mathrm{e} 3}$ \\
\cline { 2 - 4 } & \multicolumn{2}{|c}{ Generalisation stage } \\
\hline determination coefficient $\left(R^{2}\right)$ & 0.9964 & 0.9969 & 0.9939 \\
\hline correlation coefficient $(R)$ & 0.9982 & 0.9984 & 0.9969 \\
\hline slope $(\alpha)$ & 0.9925 & 0.9987 & 0.9920 \\
\hline intercept $(\beta)$ & 0.0488 & -0.0001 & -0.020 \\
\hline mean squared error $(\mathrm{MSE})$ & $\mathbf{1 . 3 5 7 1}$ & $\mathbf{0 . 1 3 6 4}$ & $\mathbf{0 . 2 8 2 6}$ \\
\hline
\end{tabular}
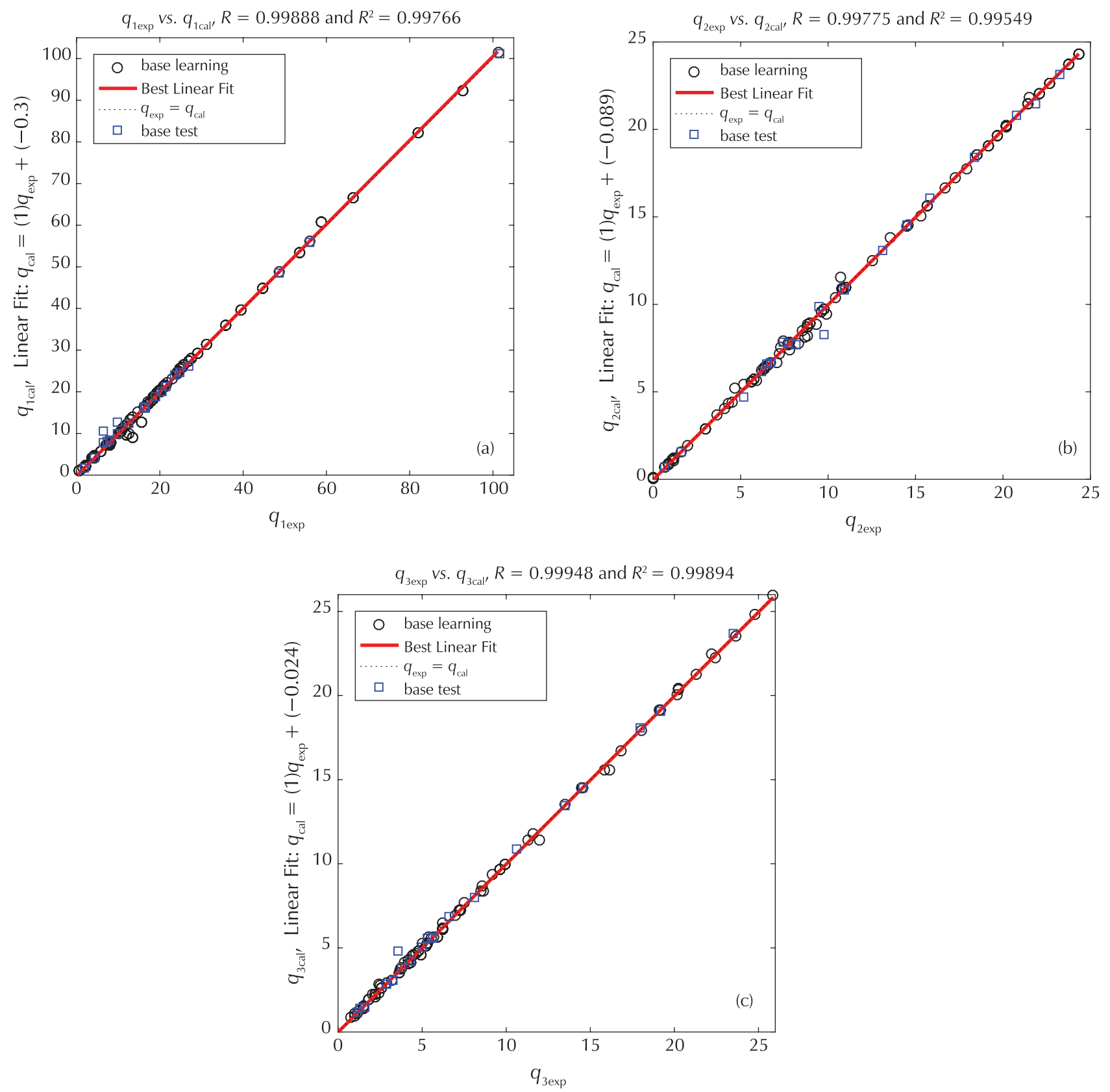

Fig. 5 - Predicted vs experimental adsorption capacity using SVR, a) for $q_{\mathrm{e} 1}$, b) for $q_{\mathrm{e} 2}$, and c) for $q_{\mathrm{e} 3}$ 
that $R^{2}$ was higher than 0.99, and Table 9 shows that the maximum MSE was 0.8983. This result explains the higher capability of this model in fitting the multicomponent adsorption systems.

Table 9 - Computed errors comparison results obtained by SVR

\begin{tabular}{l|c|c|c}
\hline \multirow{2}{*}{$\begin{array}{r}\text { Removal } \\
\text { capacity }\end{array}$} & $q_{\mathrm{e} 1}$ & $q_{\mathrm{e} 2}$ & $q_{\mathrm{e} 3}$ \\
\cline { 3 - 4 } ptatistical & \multicolumn{2}{|c}{ Generalisation stage } \\
\hline determination coefficient $\left(R^{2}\right)$ & 0.9977 & 0.9955 & 0.9989 \\
\hline correlation coefficient $(R)$ & 0.9989 & 0.9977 & 0.9995 \\
\hline slope $(\alpha)$ & 1.0093 & 1.0055 & 0.9990 \\
\hline intercept $(\beta)$ & -0.3023 & -0.0893 & -0.024 \\
\hline mean squared error $(\mathrm{MSE})$ & $\mathbf{0 . 8 9 8 3}$ & $\mathbf{0 . 1 9 5 7}$ & $\mathbf{0 . 0 4 8 2}$ \\
\hline
\end{tabular}

By comparison, ANN and LS-SVR with SVR, the latter shows good performance in prediction accuracy and computational speed (Fig. 6).

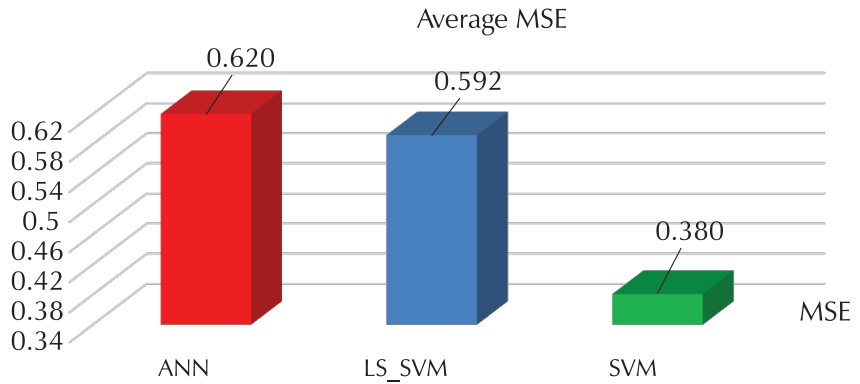

Fig. 6 - Average MSE obtained by ANN, LS-SVR, and SVR

\section{Conclusions}

This work aimed to model a ternary adsorption system of different heavy metals on several adsorbents, using ANN, SVR, and LS-SVR models. The optimised static neural network was found with a structure of $\{8-6-3\}$, tangent sigmoid activation function for the hidden and the linear for the output layer, Levenberg-Marquardt learning algorithm. The best ANN was found with a coefficient of determination $R^{2}=[0.9960,0.9957,0.9958]$ and a mean squared error MSE $=[1.4898,0.1780,0.1912]$ for the three outputs for the global data set. The optimised least squared support vector regression model was found with a coefficient of determination $R^{2}=[0.9964,0.9969,0.9939]$ and a mean squared error (MSE) $=[1.3571,0.1364,0.2826]$ for the three outputs for the global data set. The optimised support vector regression model was found with a coefficient of determination $R^{2}=[0.9977,0.9955,0.9989]$ and a mean squared error (MSE) $=[0.8983,0.1957,0.0482]$ for the three outputs and for the global data set.
The obtained results showed that the three models exhibited good aptitudes for predicting the adsorbed quantities, although a slight preference goes for the SVR model.

\section{References \\ Literatura}

1. Y. Sheth, S. Dharaskar, M. Khalid, S. Sonawane, An environment friendly approach for heavy metal removal from industrial wastewater using chitosan based biosorbent: A review, Sustain. Energy Technol. Assess. 43 (2021) 100951, doi: https://doi.org/10.1016/j.seta.2020.100951.

2. N. H. Yusof, K. Y. Foo, B. H. Hameed, M. H. Hussin, H. K. Lee, S. Sabar, One-step synthesis of chitosan-polyethyleneimine with calcium chloride as effective adsorbent for Acid Red 88 removal, Int. J. Biol. Macromol. 157 (2020) 648-658, doi: https://doi.org/10.1016/j.ijbiomac.2019.11.218.

3. B. Anna, M. Kleopas, S. Constantine, F. Anestis, B. Maria, Adsorption of $\mathrm{Cd}(\mathrm{II}), \mathrm{Cu}(\mathrm{II}), \mathrm{Ni}(\mathrm{II})$ and $\mathrm{Pb}(\mathrm{II})$ onto natural bentonite: study in mono- and multi-metal systems, Environ. Earth Sci. 73 (2015) 5435-5444, doi: https://doi. org/10.1007/s12665-014-3798-0.

4. C. Namasivayam, D. Sangeetha, R. Gunasekaran, Removal of anions, heavy metals, organics and dyes from water by adsorption onto a new activated carbon from Jatropha husk, an agro-industrial solid waste, Process Saf. Environ. Prot. 85 (2007) 181-184, doi: https://doi.org/10.1205/psep05002.

5. A. Maleki, B. Hayati, F. Najafi, F. Gharibi, S. W. Joo, Heavy metal adsorption from industrial wastewater by PAMAM/ $\mathrm{TiO}_{2}$ nanohybrid: Preparation, characterization and adsorption studies, J. Mol. Liquid. 224 (2016) 95-104, doi: https:// doi.org/10.1016/j.molliq.2016.09.060.

6. M. E. Mesquita, J. M. Vieira e Silva, Preliminary study of $\mathrm{pH}$ effect in the application of Langmuir and Freundlich isotherms to $\mathrm{Cu}-\mathrm{Zn}$ competitive adsorption, Geoderma 106 (2002) 219-234, doi: https://doi.org/10.1016/S00167061(01)00125-2.

7. P. S. Pauletto, G. L. Dotto, N. P. G. Salau, Optimal artificial neural network design for simultaneous modeling of multicomponent adsorption, J. Mol. Liquid. 320 (2020) 114418, doi: https://doi.org/10.1016/j.molliq.2020.114418.

8. E. Byvatov, U. Fechner, J. Sadowski, G. Schneider, Comparison of Support Vector Machine and Artificial Neural Network Systems for Drug/Nondrug Classification, J. Chem. Inf. Comput. Sci. 43 (2003) 1882-1889, doi: https://doi. org/10.1021/ci0341161.

9. R. M. Aghav, S. Kumar, S. N. Mukherjee, Artificial neural network modeling in competitive adsorption of phenol and resorcinol from water environment using some carbonaceous adsorbents, J. Hazard. Mater. 188 (2011) 67-77, doi: https:// doi.org/10.1016/j.jhazmat.2011.01.067.

10. A. R. Bagheri, M. Ghaedi, A. Asfaram, S. Hajati, A. M. Ghaedi, A. Bazrafshan, M. R. Rahimi, Modeling and optimization of simultaneous removal of ternary dyes onto copper sulfide nanoparticles loaded on activated carbon using second-derivative spectrophotometry, J. Taiwan Inst. Chem. Eng. 65 (2016) 212-224, doi: https://doi.org/10.1016/j.jtice.2016.05.004.

11. P. S. Pauletto, J. O. Gonçalves, L. A. A. Pinto, G. L. Dotto, N. $P$. G. Salau, Single and competitive dye adsorption onto chitosan-based hybrid hydrogels using artificial neural network modeling, J. Colloid Interface Sci. 560 (2020) 722-729, doi: https://doi.org/10.1016/j.jcis.2019.10.106.

12. D. I. Mendoza-Castillo, H. E. Reynel-Ávila, F. J. Sánchez-Ruiz, R. Trejo-Valencia, J. E. Jaime-Leal, A. Bonilla-Petriciolet, In- 
sights and pitfalls of artificial neural network modeling of competitive multi-metallic adsorption data, J. Mol. Liquid. 251 (2018) 15-27, doi: https://doi.org/10.1016/j.molliq.2017.12.030.

13. A. Gopinath, B. G. Retnam, A. Muthukkumaran, K. Aravamudan, Swift, versatile and a rigorous kinetic model based artificial neural network surrogate for single and multicomponent batch adsorption processes, J. Mol. Liquid. 297 (2020) 111888, doi: https://doi.org/10.1016/j.molliq.2019.111888.

14. P. S. Pauletto, S. F. Lütke, G. L. Dotto, N. P. G. Salau, Forecasting the multicomponent adsorption of nimesulide and paracetamol through artificial neural network, Chem. Eng. J. (2020) 127527, doi: https://doi.org/10.1016/j.cej.2020.127527.

15. J. J. González Costa, M. J. Reigosa, J. M. Matías, E. F. Covelo, Soil $\mathrm{Cd}, \mathrm{Cr}, \mathrm{Cu}, \mathrm{Ni}, \mathrm{Pb}$ and $\mathrm{Zn}$ sorption and retention models using SVM: Variable selection and competitive model, Sci. Total Environ. 593-594 (2017) 508-522, doi: https://doi. org/10.1016/j.scitotenv.2017.03.195.

16. Y. Wang, J. Chen, W. Tang, D. Xia, Y. Liang, X. Li, Modeling adsorption of organic pollutants onto single-walled carbon nanotubes with theoretical molecular descriptors using MLR and SVM algorithms, Chemosphere 214 (2019) 79-84, doi: https://doi.org/10.1016/j.chemosphere.2018.09.074.

17. Z. U. Ahmad, L. Yao, Q. Lian, F. Islam, M. E. Zappi, D. D. Gang, The use of artificial neural network (ANN) for modeling adsorption of sunset yellow onto neodymium modified ordered mesoporous carbon, Chemosphere 256 (2020) 127081, doi: https://doi.org/10.1016/j.chemosphere.2020.127081.

18. M. Moussaoui, M. Laidi, S. Hanini, M. Hentabli, Artificial Neural Network and Support Vector Regression Applied in Quantitative Structure-property Relationship Modelling of Solubility of Solid Solutes in Supercritical $\mathrm{CO}_{2}$, Kem. Ind. 69 (11-12) (2020) 611-630, doi: https://doi.org/10.15255/ KUI.2020.004.

19. Y. Kumar, L. Singh, V. S. Sharanagat, A. Tarafdar, Artificial neural network (ANNs) and mathematical modelling of hydration of green chickpea, Inf. Process. Agricult. (2020) 1-12, doi: https://doi.org/10.1016/j.inpa.2020.04.001.

20. L.-J. Cao, F. E. H. Tay, Support vector machine with adap- tive parameters in financial time series forecasting, IEEE Trans. Neural Netw. 14 (2003) 1506-1518, doi: https://doi. org/10.1109/tnn.2003.820556.

21. S. Zhou, X. Chu, S. Cao, X. Liu, Y. Zhou, Prediction of the ground temperature with ANN, LS-SVM and fuzzy LS-SVM for GSHP application, Geothermics 84 (2020) 101757, doi: https://doi.org/10.1016/j.geothermics.2019.101757.

22. K. Kadirvelu, J. Goel, Cjj. Rajagopal, Sorption of lead, mercury and cadmium ions in multi-component system using carbon aerogel as adsorbent, J. Hazard. Mater. 153 (2008) 502507, doi: https://doi.org/10.1016/j.jhazmat.2007.08.082.

23. Y. Zhu, J. Hu, J. Wang, Competitive adsorption of $\mathrm{Pb}$ (II), $\mathrm{Cu}$ (II) and Zn (II) onto xanthate-modified magnetic chitosan, J. Hazard. Mater. 221 (2012) 155-161, doi: https://doi. org/10.1016/j.jhazmat.2012.04.026.

24. F. Qin, B. Wen, X.-Q. Shan, Y.-N. Xie, T. Liu, S.-Z. Zhang, S. $U$. Khan, Mechanisms of competitive adsorption of $\mathrm{Pb}, \mathrm{Cu}$, and Cd on peat, Environ. Pollut. 144 (2006) 669-680, doi: https://doi.org/10.1016/j.envpol.2005.12.036.

25. M. Jain, V. K. Garg, K. Kadirvelu, M. Sillanpää, Adsorption of heavy metals from multi-metal aqueous solution by sunflower plant biomass-based carbons, Int. J. Environ. Sci. Technol. 13 (2016) 493-500, doi: https://doi.org/10.1007/s13762015-0855-5.

26. D. Mohan, K. P. Singh, Single-and multi-component adsorption of cadmium and zinc using activated carbon derived from bagasse - an agricultural waste, Water Res. 36 (2002) 2304-2318, doi: https://doi.org/10.1016/S00431354(01)00447-X.

27. C. M. Amado, C. J. Minahk, E. Cilli, G. Oliveira, F. G. Dupuy, Bacteriocin enterocin CRL35 is a modular peptide that induces non-bilayer states in bacterial model membranes, BBA - Biomembranes 1862 (2) (2019) 183135, doi: https:// doi.org/10.1016/j.bbamem.2019.183135.

28. H. Benimam, C. Si-Moussa, M. Laidi, S. Hanini, Modeling the activity coefficient at infinite dilution of water in ionic liquids using artificial neural networks and support vector machines, Neural Comput. Appl. 32 (2020) 8635-8653, doi: https:// doi.org/10.1007/s00521-019-04356-w. 


\section{SAŽETAK \\ Ternarno višekomponentno modeliranje adsorpcije primjenom ANN-a, LS-SVR-a i SVR-a - studija slučaja

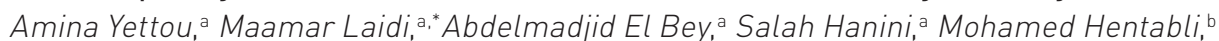 Omar Khaldi, ${ }^{\mathrm{c}}$ and Mihoub Abderrahima}

Cilj ovog rada bio je razviti tri metode temeljene na umjetnoj inteligenciji za modeliranje trostruke adsorpcije iona teških metala $\left\{\mathrm{Pb}^{2+}, \mathrm{Hg}^{2+}, \mathrm{Cd}^{2+}, \mathrm{Cu}^{2+}, \mathrm{Zn}^{2+}, \mathrm{Ni}^{2+}, \mathrm{Cr}^{4+}\right\}$ na različitim adsorbatima \{aktivni ugljen, kitozan, danski treset, treset Heilongjiang, ugljik glave suncokreta i ugljik stabljike suncokreta). Rezultati pokazuju da se regresija potpornih vektora (SVR) pokazala nešto boljom, preciznijom, stabilnijom i bržom od regresije potpornih vektora najmanjih kvadrata (LS-SVR) i umjetnih neuronskih mreža (ANN). Za procjenu kinetike trostrukog adsorpcijskog sustava višekomponentnog sustava preporučuje se model SVR.

\section{Ključne riječi}

Višekomponentna adsorpcija, teški metali, umjetne neuronske mreže, regresija potpornih vektora, regresija potpornih vektora najmanjih kvadrata

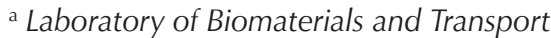

Izvorni znanstveni rad Phenomena (LBMPT),

University of Médéa, Algeria

b Laboratory Quality Control,

Physico-Chemical Department,

Antibiotical Saidal of Médéa, Algeria

c Material and Environment Laboratory (LME),

University Yahia Fares of Medea,

Médéa, Algeria 